\title{
The PL Characteristics of ZnO Thin Film on Flexible Polymer by Pulse Laser Deposition
}

\author{
Young Jin Choi and Cheon Lee ${ }^{\dagger}$ \\ Department of Electronic Engineering, Inha University, Incheon 402-751, Korea
}

Received August 24, 2012; Revised August 29, 2012; Accepted August 29, 2012

\begin{abstract}
In this study, ZnO films have been grown on PES (polyethersulfone) of flexible polymer substrate by PLD (pulsed laser deposition) and characterized for crystalline and optical properties. Growing conditions were changed with substrate temperatures ranging from 50 to $200^{\circ} \mathrm{C}$ and laser power density ranging from 0.2 to $0.4 \mathrm{~J} / \mathrm{cm}^{2}$. When $\mathrm{ZnO}$ thin films are deposited at low temperature with a small laser power density, the (002) peaks of XRD to signify the crystal quality of $\mathrm{ZnO}$ thin films appear to be very weak and the (101) peaks to signify the chemical composition of oxygen and zinc are strong. The (002) peaks increase with the substrate temperature and laser power density because the energy needed for the supply of the combination regarding zinc and oxygen has increased. In this study, the best condition for growing $\mathrm{ZnO}$ thin film on PES is at a substrate temperature of $200{ }^{\circ} \mathrm{C}$ and with a laser density of $0.3 \mathrm{~J} / \mathrm{cm}^{2}$. The characteristics of PL were measured by UV and green luminescence.
\end{abstract}

Keywords: ZnO, Pulse laser deposition, Flexible substrate, Polyethersulfone

\section{INTRODUCTION}

$\mathrm{ZnO}$ is a wide-band gap $\mathrm{II}-\mathrm{VI}$ compound semiconductor and has a hexagonal wurtzite structure [1]. ZnO can be used as SAW (Surface acoustic wave), LED (light emitting diode), TCO (transparent conducting oxide) devices, and a gas sensor because of its various optical and electric characteristics. One of the important characteristics is a wide band gap of $3.37 \mathrm{eV}$ at $300 \mathrm{~K}$, and is an attractive compound for use in ultraviolet light emitting diodes and lasers. It shows pronounced excitonic effects at room temperature due to its large exciton binding energy $(59 \mathrm{meV})[2,3]$.

Various deposition techniques as molecular beam epitaxy, RF magnetron sputtering, chemical vapor deposition, sol-gel and pulse laser deposition have been used for the production of $\mathrm{ZnO}$ thin films with properties for the specific application. PLD (pulsed laser deposition) is expected to be a rather appropriate technique for tailoring the nanostructure of $\mathrm{ZnO}$ films during growth because it offers the advantage of producing high quality

${ }^{\dagger}$ Author to whom all correspondence should be addressed:

E-mail: chnlee@inha.ac.kr

Copyright $@ 2012$ KIEEME. All rights reserved.

This is an open-access article distributed under the terms of the Creative Commons Attribution Non-Commercial
License (http:///creativecommons.org/licenses/by-nc/3.0) which permits unrestricted noncommercial use, distribution, and reproduction in any medium, provided the original work is property cited. films at relatively lower temperatures with high deposition rates, process stability, and repeatability [4].

Polymer substrates have attracted attention for a long time because it is a suitable material for the production of the flexible display. However, the high-quality thin film deposition on polymer substrates using high temperature processes is very difficult because most of the polymer material has both a low thermal strain and melting temperature.

$\mathrm{ZnO}$ demonstrates good compatibility with plastic or flexible substrate materials because quality polycrystalline films with moderate Hall mobilities ( $>1 \mathrm{~cm}^{2} / \mathrm{Vs}$ ) can be made at room temperature $[5,6]$. Therefore, we have grown the $\mathrm{ZnO}$ thin film on polymer substrates of polyethersulfone by PLD at low temperature.

\section{EXPERIMENTAL}

In this study, A Quantel Brillant B Q-switched $4^{\text {th }}$ harmonic Nd:YAG laser $(\lambda=266 \mathrm{~nm})$ with a fluence maximum of $0.7 \mathrm{~J} / \mathrm{cm} 2$ and a repetition rate of $10 \mathrm{~Hz}$ was used to deposit $\mathrm{ZnO}$ thin films by PLD. The used laser power density ranged from 0.2 to $0.4 \mathrm{~J} /$ $\mathrm{cm}^{2}$. The chamber for growing was initially evacuated to $10^{-5}$ Torr 


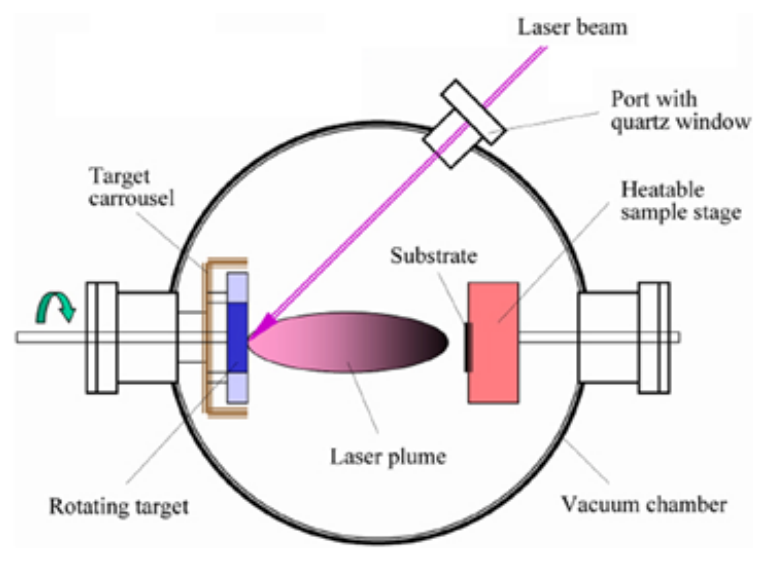

Fig. 1. A schematic diagram of the PLD system.

Table 1. The pulse laser deposition conditions.

\begin{tabular}{lc}
\hline Laser Power Density & $0.2,0.3$, and $0.4 \mathrm{~J} / \mathrm{cm}^{2}$ \\
Substrate Temperature & $50,100,150$, and $200{ }^{\circ} \mathrm{C}$ \\
Substrate Material & PES (polyethersulfone) $1 \times 1 \times 0.2 \mathrm{~cm}^{3}$ \\
Target Material & A purity of $99.99 \% \mathrm{ZnO}$ \\
\hline
\end{tabular}

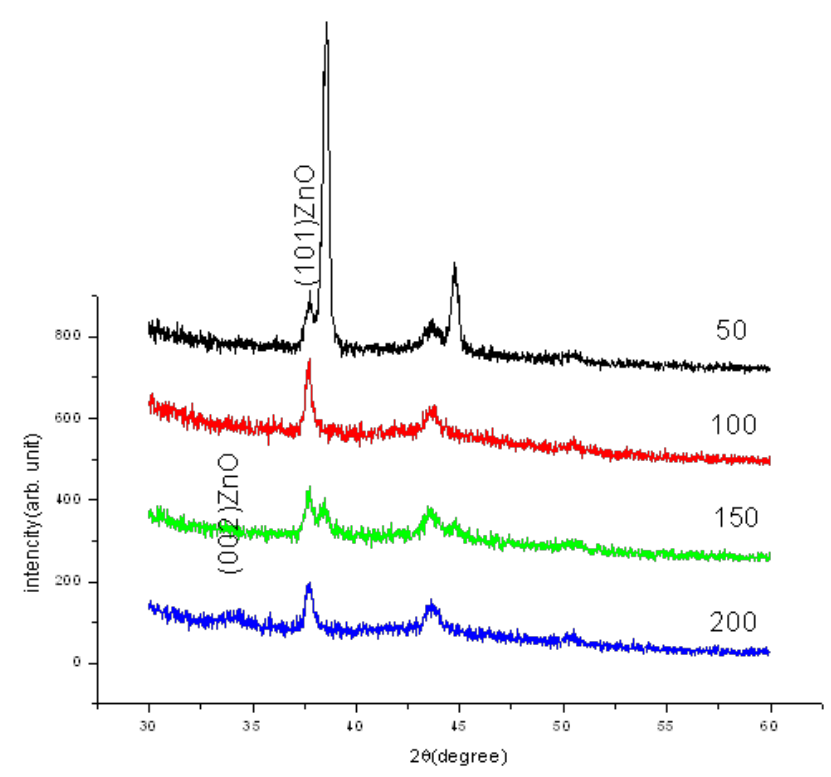

Fig. 2. XRD patterns of the $\mathrm{ZnO}$ thin film deposited with a laser density of $0.3 \mathrm{~J} / \mathrm{cm}^{2}$ at a substrate temperature of $50,100,150$, and $200{ }^{\circ} \mathrm{C}$

with an oil diffusion pump and a rotary pump. The targets used to deposit thin films were of a $\mathrm{ZnO}$ purity of $99.99 \%$. The target was rotated at a constant speed of about $4 \mathrm{rpm}$ so that the laser beam would be irradiated on different areas. The substrates were located $50 \mathrm{~mm}$ away from the target at varying temperatures in a $50 \sim 200^{\circ} \mathrm{C}$. A PES (polyethersulfone) of $1 \mathrm{~cm} \times 1 \mathrm{~cm} \times 0.2 \mathrm{~cm}$ was used as flexible substrate. In order to remove organic particles, PES substrates were cleaned in an ultrasonic bath with isopropyl alcohol and distilled water for 30 seconds, and then dried by a $\mathrm{N}_{2}$ gun. Figure 1 is a schematic diagram of the PLD system used in this study. The pulse laser deposition conditions are shown as Table 1.

Structure properties of film were investigated by X-ray diffraction (XRD). ZnO thin film surface properties were observed by scanning electron microscopy (SEM). The optical properties of

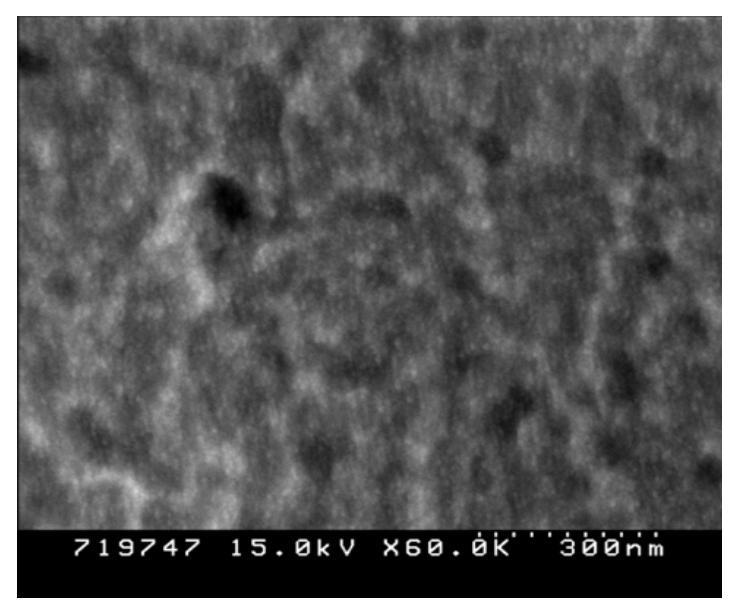

Fig. 3. SEM image of the $\mathrm{ZnO}$ thin film deposited with a laser density of $0.3 \mathrm{~J} / \mathrm{cm}^{2}$ at a substrate temperature of $200^{\circ} \mathrm{C}$.

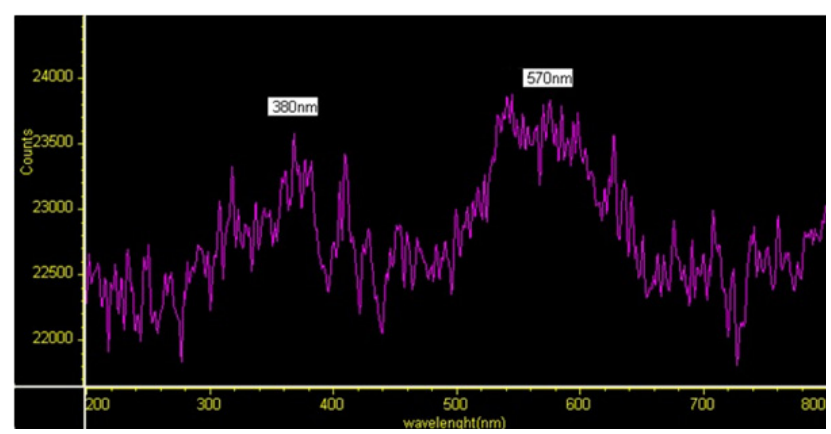

Fig. 4. PL spectra at room temperature of the $\mathrm{ZnO}$ thin film deposited with a laser density of $0.3 \mathrm{~J} / \mathrm{cm}^{2}$ at a substrate temperature of $200^{\circ} \mathrm{C}$.

the $\mathrm{ZnO}$ thin film were characterized by photoluminescence (PL).

\section{RESULTS AND DISCUSSION}

The thickness of the grown $\mathrm{ZnO}$ thin films was measured as approximately $200 \mathrm{~nm}$ in this study.

Figure 2 shows XRD patterns of the $\mathrm{ZnO}$ thin film deposited with a laser density of $0.3 \mathrm{~J} / \mathrm{cm}^{2}$ at a substrate temperature of 50 , 100,150 , and $200^{\circ} \mathrm{C}$, respectively. The (002) peak of $\mathrm{ZnO}$ is almost not observed at temperatures of less than $200^{\circ} \mathrm{C}$. It is thought to cause an imperfect bond of oxygen and zinc by the lack of thermal energy supplied to the substrate. It seems that the crystallinity of $\mathrm{ZnO}$ thin film improves if oxygen supply or substrate temperature is increased.

Figure 3 shows the SEM image of the $\mathrm{ZnO}$ thin film deposited at a substrate temperature of $200^{\circ} \mathrm{C}$ and a laser density of $0.3 \mathrm{~J} /$ $\mathrm{cm}^{2}$. The surface of thin film shows high roughness and porosity for requisite oxygen vacancy in regards to the oxygen-zinc bond. This result is consistent with the (101) peak of XRD shown as Fig. 2 .

Figure 4 is the PL spectra of the $\mathrm{ZnO}$ thin film deposited at a substrate temperature of $200^{\circ} \mathrm{C}$ and a laser density of $0.3 \mathrm{~J} / \mathrm{cm}^{2}$. The PL is measured at room temperature when the $\mathrm{ZnO}$ thin film exhibits PL intensity at $380 \mathrm{~nm}$ and $570 \mathrm{~nm}$ wavelength. The peak of $380 \mathrm{~nm}$ is smaller than the peak of $570 \mathrm{~nm}$. This is caused by point defects. UV luminescence at approximately $380 \mathrm{~nm}$ is produced by exciton annihilation. The broad photoluminescence at about $570 \mathrm{~nm}$ has actually been reported by many researchers 
in bulk $\mathrm{ZnO}$ as well as in $\mathrm{ZnO}$ quantum dots. However, the exact origin of this emission band has still not been fully understood. It seems that the green emission to point defect by oxygen vacancy occurs.

\section{CONCLUSIONS}

In this study, ZnO films have been grown on PES (polyethersulfone) substrate by pulsed laser deposition. When $\mathrm{ZnO}$ thin films are deposited at low temperature with a small laser power density, the (002) peaks of XRD to signify the crystal quality of $\mathrm{ZnO}$ thin films are shown to be very weak and the (101) peaks to signify the chemical composition of oxygen and zinc are strong. The (002) peaks of XRD increase with the substrate temperature and laser power density because the energy needed for the supply of the combination regarding zinc and oxygen has increased. However, excessively increasing the laser density reduces the deposition rate with the film thickness. The best condition for growing $\mathrm{ZnO}$ thin film on PES is at a substrate temperature of $200^{\circ} \mathrm{C}$ and with a laser density of $0.3 \mathrm{~J} / \mathrm{cm}^{2}$ in this study. The characteristics of PL were measured by UV and green luminescence.

\section{ACKNOWLEDGMENTS}

This research was supported by the MKE(The Ministry of Knowledge Economy), Korea, under the ITRC(Information Technology Research Center) support program supervised by the NIPA(National IT Industry Promotion Agency) (NIPA2012-H0301-12-1010).
This research was supported by Inha University Research Grant of 2012.

\section{REREFENCES}

[1 ] P. Nunes, E. Fortunato, P. Tonello, F. Braz Fernandes, P. Vilarinho and R. Martins, "Effect of different dopant elements on the properties of ZnO thin films ", Vacuum, Vol. 64, 281 (2002) [DOI: http://dx.doi.org/10.1016/S0042-207X(01)00322-0].

[2] H. Kim, A. Pique, J. S, "Effect of aluminum doping on zinc oxide thin films grown by pulsed laser deposition for organic lightemitting devices", Thin Solid Films, Vol. 377, 798 (2000) [DOI: http://dx.doi.org/10.1016/S0040-6090(00)01290-6].

[3] A. Mitra, R. K. Tharja, "Synthesis and characterization of $\mathrm{ZnO}$ thin films for UV laser”, Applied Surface Science, Vol. 174, 232 (2001). http://dx.doi.org/10.1016/S0169-4332(01)00171-4

[4] Deuk-Hee Lee, Yoon Soo Chun, Sang Yeol Lee, Sangsig Kim, "Evaluation of Acceptor Binding Energy of Nitrogen- Doped Zinc Oxide Thin Films Grown by Dielectric Barrier Discharge in Pulsed Laser Deposition", TEEM, Vol. 12, no. 5, pp.200-203 (2011) [DOI: http://dx.doi.org/10.4313/TEEM.2011.12.5.200].

[5] K. Ellmer, K. Diesner, R. Wendt, S. Fiechter, "Relations between Texture and Electrical Parameters of Thin Polycrystalline Zinc Oxide Films" Solid State Phenom. 51, 541 (1996) [DOI: http:// dx.doi.org/10.4028/www.scientific.net/SSP.51-52.541].

[6] W. J. Jeong, G. C. Park, "Electrical and optical properties of $\mathrm{ZnO}$ thin film as a function of deposition parameters" Sol. Energy Mater. \& Sol. Cells, Vol. 65, 37 (2001) [DOI: http://dx.doi. org/10.1016/S0927-0248(00)00075-1]. 